\title{
On Ancient Indian history: What do we know and how? By Rajesh Kochhar
}

\author{
Published online 5 July 2019
}

Keywords. Vedic People; Rigveda; ancient India; Harappan civilization; genomics; Indo-European speakers

Dr Rajesh Kochhar, Professor of Astrophysics, and at that time Director of the National Institute of Science, Technology and Development Studies (New Delhi), published in 2000 a book entitled The Vedic people: Their History and Geography (Orient Longman Ltd.). In his preface, Kochhar noted:

Reconstruction of the past is an important part of the exercise of nation building. A nation's heritage should be based on hard, scientifically tested facts and not on vague notions born out of cultivated ignorance.

As an experienced scientist, Kochhar ventured outside his own fields of specialization to include philology, archaeology and linguistics in his attempt to build up his own logical reconstruction of India's prehistory, as a corrective to widely publicized, nationalistically biased and politically motivated claims based on shaky foundations. The impressive result is, in my opinion, still largely valid - the reconstruction does not essentially differ from my own 15-years-younger synthesis (The Roots of Hinduism: The Early Aryans and the Indus Civilization, OUP 2015). Kochhar's book richly repays study even now.

The summarizing paper published here contains some mistakes or inaccuracies not found in Kochhar's book, such as, "Before the dispersals began, PIE had domesticated horse (Skt ashva=Gothic athwa), harnessed it in fast-moving spokewheeled vehicles (Skt chakra=Greek kyklos=Engl. cycle), and learnt the use of copper (ayas=eos).” The Proto-Indo-European (PIE) speakers certainly knew the horse (correct the Gothic counterpart of Sanskrit aśva into aihva), but in PIE the word for 'wheel' (Sanskrit cakra, Greek kuklos, English wheel-cycle in English is a late borrowing from Latin cyclus) denoted solid wheels used in oxen-pulled heavy wagons and carts - invented about 3600 BCE, while the fast-moving horse-drawn chariot having spoked wheels was invented in the Sintashta culture of the Uralic steppes in Russia about 2100 BCE, long after the final dispersal of the PIE speakers, which took place about 3000-2900 BCE. (On these points Kochhar writes more correctly in his book, pp. 147-150.) Instead of the ghost-word eos mentioned in the above quote as the counterpart of Sanskrit ayas, 'copper', read Latin aes (correctly so, p. 145 of Kochhar's book, which also mentions English ore.) “The Indo-Iranians $\ldots$ are the only ones in the entire PIE family who would produce literature: Rigveda (Rv) and the related Avesta.” This is a strange statement: The Indo-Iranian speakers of the late second millennium BCE were certainly not the only descendants of Proto-Indo-European speakers to produce literature, although they did this remarkably early: proper literature in the Greek language, for instance, begins about $800 \mathrm{BCE}$, yet Greek was written in economic documents already around $1200 \mathrm{BCE}$. Some original slips (such as RV 8,80 instead of 8,91 as the Apālā hymn, p. 99) are also repeated here.

Asko PARPOLA University of Helsinki, Helsinki, Finland (Email,Asko.Parpola@Helsinki.Fi) 